\title{
Behaviour of Azospirillum brasilense in a spatial gradient of oxygen and in a 'redox' gradient of an artificial electron acceptor
}

\author{
Ruslan N. Grishanin, Irina I. Chalmina and Igor B. Zhulin* \\ Laboratory of Bioenergetics, Institute of Biochemistry and Physiology of Plants and Microorganisms, \\ USSR Academy of Sciences, pr. Entuziastov 13, Saratov, 410015 USSR
}

(Received 17 June 1991; revised 15 August 1991; accepted 28 August 1991)

\begin{abstract}
Azospirillum brasilense responds to a spatial gradient of oxygen by formation of a band in the zone of optimal oxygen concentration. The same behaviour was observed in a 'redox' gradient of tetramethyl-p-phenylenediamine (TMPD) oxidized by ferricyanide, under conditions where oxygen uptake was inhibited by cyanide. Inhibitors of the $b c_{1}$-complex of the redox chain did not inhibit aerotaxis. Cells inhibited by a high cyanide concentration still showed slow motility and weak attraction to oxygen, possibly as a result of cyanide-resistant respiration (3-5\% of the initial level). It is suggested that electron flow through the redox chain (and/or consequent changes in protonmotive force), rather than binding of oxygen to terminal oxidases, may be a signal in the aerotactic response of $A$. brasilense.
\end{abstract}

\section{Introduction}

Aerotaxis, defined as a migration in response to a gradient of oxygen is a common behavioural response in aerobic, microaerophilic and anaerobic bacteria (for reviews, see Taylor, 1983a, b). Aerotaxis appears to enable the bacteria to accumulate at concentrations of oxygen that are optimal for respiration whilst avoiding the harmful side effects of unnecessarily high concentrations of oxygen (Shioi et al., 1987).

Azospirillum brasilense, a nitrogen-fixing bacterium typical of the rhizosphere of higher plants, has a respiratory type of metabolism (Martinez-Drets et al., 1984), but is capable of fixing nitrogen only at a low concentration of oxygen (Nelson \& Knowles, 1978). Hence, locating the very narrow zone of optimal oxygen concentration in natural gradients is very important for these micro-organisms. Microaerobic conditions are typical of plant rhizospheres, so aerotaxis may be an important step in establishing interrelationships between bacteria and plants (Okon \& Kapulnik, 1986).

$A$. brasilense responds to a spatial gradient of oxygen by forming a band of bacteria in a suspension (Barak $e t$ al., 1982). Such band formation is considered to occur as a result of the dual action of oxygen as attractant and repellent (Shioi et al., 1987). Two different primary 'receptors' that bind oxygen, one for the positive

Abbreviations: HQNO, 2-heptyl-4-hydroxyquinoline $N$-oxide; TMPD, $N, N, N^{\prime}, N^{\prime}$-tetramethyl-p-phenylenediamine. response and another for the negative, have been suggested. Terminal oxidases of the redox chain are positive 'receptors' (Laszlo et al., 1984a; Shioi et al., 1988). The negative 'receptor' may be a component with low affinity for oxygen, or a component which detects toxic byproducts of oxygen reduction (Shioi et al., 1987). Initial signal transduction events in the response to oxygen include electron flow through the redox chain and consequent changes in the protonmotive force (Laszlo \& Taylor, 1981; Shioi \& Taylor, 1984; Taylor, $1983 a, b)$. The change in protonmotive force may then be detected by a hypothetical receptor, the 'protometer' (Glagolev, 1980), that transmits the signal via a common signalling system to the flagellar motor (Rowsell et al., 1988). This hypothetical model (Glagolev, 1980; Taylor, $1983 a, b)$ was supported by experiments on Escherichia coli and Salmonella typhimurium (Laszlo \& Taylor, 1981; Shioi \& Taylor, 1984; Shioi et al., 1988), Bacillus cereus (Laszlo et al., 1984b) and Rhodobacter sphaeroides (Armitage et al., 1985). Nevertheless, $A$. brasilense has been reported to possess a different type of sensory transduction pathway for aerotaxis. It was suggested that oxygen recognition in aerotaxis might occur via the redox state of cytochrome $o$, one of three terminal oxidases in $A$. brasilense (Reiner \& Okon, 1986).

In this study a functioning redox chain was shown to be essential for aerotaxis in $A$. brasilense; however, terminal oxidases per se do not appear to be directly involved in signal transduction. 


\section{Methods}

Bacterial strain and growth medium. Azospirillum brasilense $\mathrm{Sp} 7$ (ATCC 29145) was grown in the defined medium of Nelson \& Knowles (1978). Difco agar $(0.3 \%)$ was added to obtain a semi-solid medium. The liquid medium was supplemented with $0.5 \mathrm{~g} \mathrm{NH}_{4} \mathrm{Cll}^{-1}$ as nitrogen source. Stock cultures were kept on semi-solid medium at $4{ }^{\circ} \mathrm{C}$ and a new stock was used for each experiment.

Culture conditions. A loopful of stock culture was used to inoculate a $5 \mathrm{ml}$ of semi-solid medium in a test-tube. The cells developed a narrow pellicle of growth below the surface (Okon $e t$ al., 1980) as a result of aerotaxis and promoted growth under microaerobic conditions. After $72 \mathrm{~h}$ incubation, a loopful of culture from the pellicle was transferred to $100 \mathrm{ml}$ of liquid medium in a $300 \mathrm{ml}$ Erlenmeyer flask. Unless otherwise stated this was grown overnight at $30^{\circ} \mathrm{C}$ on a rotary shaker (100 r.p.m.) to the mid-exponential phase $\left(\mathrm{OD}_{530}=0.6\right.$; Spekol-221Zeiss spectrophotometer). The cells were harvested by centrifugation and washed twice with a 'chemotactic' buffer (Adler, 1973) containing $10 \mathrm{~mm}-\mathrm{KH}_{2} \mathrm{PO}_{4}, 0 \cdot 1 \mathrm{~mm}$-EDTA, $\mathrm{pH} 7 \cdot 0$. The final pellet was resuspended in the same buffer, filtered through a glass-filter to remove aggregates, diluted to the necessary concentration and shaken for $30 \mathrm{~min}$ at room temperature before use in experiments.

Taxis assays. Taxis was recorded as cell distribution in spatial gradients. Several types of assay were used. The first method for aerotaxis determination was similar to the assay described by Shioi $e t$ al. (1988). A drop of cell suspension $(70 \mu \mathrm{l})$ was placed into a microchamber constructed using a glass microscope slide as the bottom of the chamber and small pieces of a cover slip as its side walls. Then the chamber was covered by a cover slip in a manner that trapped an air bubble in the suspension. A spatial gradient of dissolved oxygen was created by both oxygen diffusion through the air/suspension interface and oxygen consumption by the respiring cells. An aerotactic band of the bacteria around the air bubble was observed through a phasecontrast 'Ergaval'-Zeiss photomicroscope.

The principle of optical density measurement of a cell suspension in a spatial gradient of an effector, created by diffusion from a gel (Zhulin $t$ al., 1991), was used to assess taxis. The microchamber described above was used as a horizontal optical cuvette. A small block of $1.5 \%$ agarose containing a chemoeffector was placed in the microchamber. The microchamber was placed on the scanning table of the microscope and densitometric scanning of the cell suspension was carried out with a photometric apparatus (FMEL-IA; LOMO, USSR), which replaced the camera on the microscope (Fig. 1). This apparatus was connected to a recorder. The halogen lamp of the microscope was used as a light source. The light-beam zone cut by the apparatus for photometric analysis was $0.1 \mathrm{~mm}$ in diameter.

Pre-formed oxygen gradients were used to investigate the behaviour of cells inhibited by cyanide. Under these conditions a spatial oxygen gradient is not sharp enough to be sensed, because oxygen consumption by the cells is inhibited. Therefore, glucose oxidation by oxygen, catalysed by glucose oxidase, was used as an artificial oxygenconsuming system within the bacterial suspension. The cell suspension to be tested contained a small amount of glucose oxidase. A block of $1.5 \%$ agarose containing $1 \mathrm{~mm}$-glucose was placed at one end of the microchamber. After addition of the cell suspension an air bubble was introduced at the other end. The distance between the bubble and the agarose block was 3-4 mm. A spatial oxygen gradient was, therefore, created both by diffusion through the air/suspension interface and by oxygen consumption by the glucose/glucose oxidase system at the other end of the microchamber. The distribution of the cell population in the pre-formed oxygen gradient was measured with the microphotometer described above.

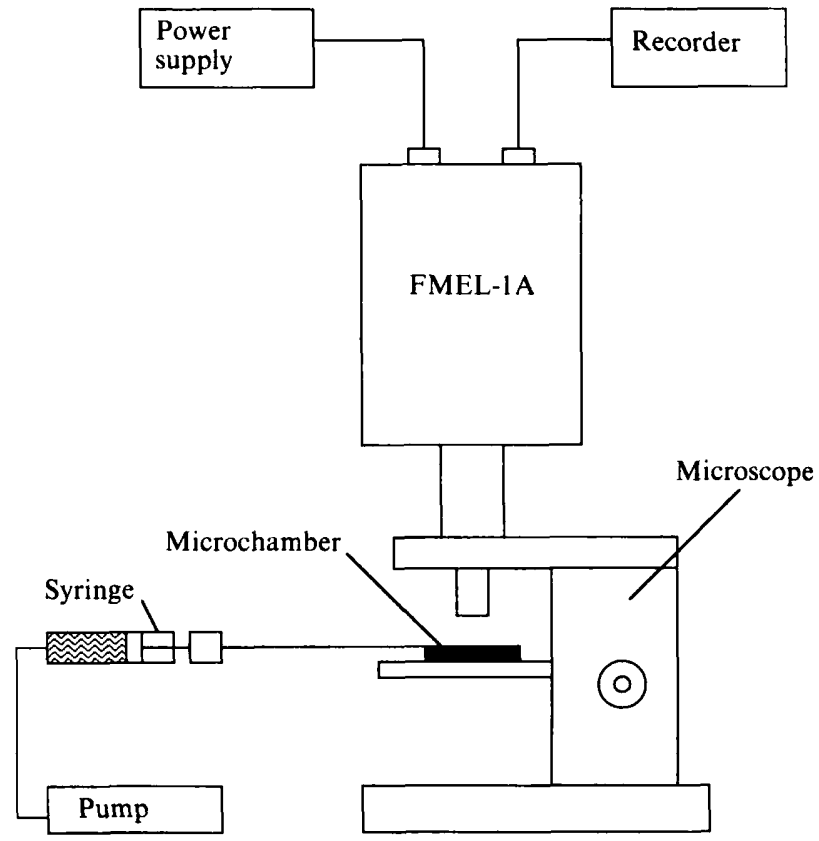

Fig. 1. Diagram of the microphotometer used in taxis assays. The scanning apparatus, which consists of a syringe and a peristaltic pump, moves the microchamber at a constant speed.

Creation of a 'redox' gradient. To create a spatial gradient of ferricyanide in isotropic $N, N, N^{\prime}, N^{\prime}$-tetramethyl-p-phenylenediamine (TMPD) an agarose block, containing the appropriate amount of potassium ferricyanide and a concentration of TMPD the same as that in the suspension under test, was placed in the microchamber. The cell suspension $\left(\mathrm{OD}_{530}=1.2\right)$ in the microchamber contained $5 \mathrm{mM}$ sodium malate as substrate, TMPD, and $20 \mathrm{mM}-\mathrm{KCN}$ to exclude oxygen gradient formation by respiring cells and to avoid the toxic byproducts of oxygen reduction. Decolorization of TMPD was observed after addition of cyanide to the suspension, which confirmed that $A$. brasilense cells reduced TMPD. A cell suspension under the same conditions, but without TMPD, was used as a control. Formation of a spatial gradient of ferricyanide in the suspension under test was observed, immediately after addition of the suspension to the microchamber, as a blue 'halo' of oxidized TMPD around the agarose block.

Measurement of oxygen uptake. The rate of oxygen uptake by a bacterial suspension was measured in a $2.5 \mathrm{ml}$ closed chamber with a Clark oxygen electrode constructed in the Department of Bioenergetics, Moscow State University. The chamber was connected to a Radelkis $\mathrm{OH}-105$ polarograph (Hungary). The measurements were carried out at $25^{\circ} \mathrm{C}$.

\section{Results and Discussion}

\section{Behaviour of $A$. brasilense in a pre-formed oxygen gradient}

The bacterial suspension $\left(\mathrm{OD}_{530}=0.8\right)$ was supplemented with $20 \mathrm{mM}-\mathrm{KCN}$ to inhibit terminal oxidases. Under these conditions oxygen uptake by the cells was 3$5 \%$ of the initial respiratory value; however, the cells still showed slow motility. Densitometric observation of the 


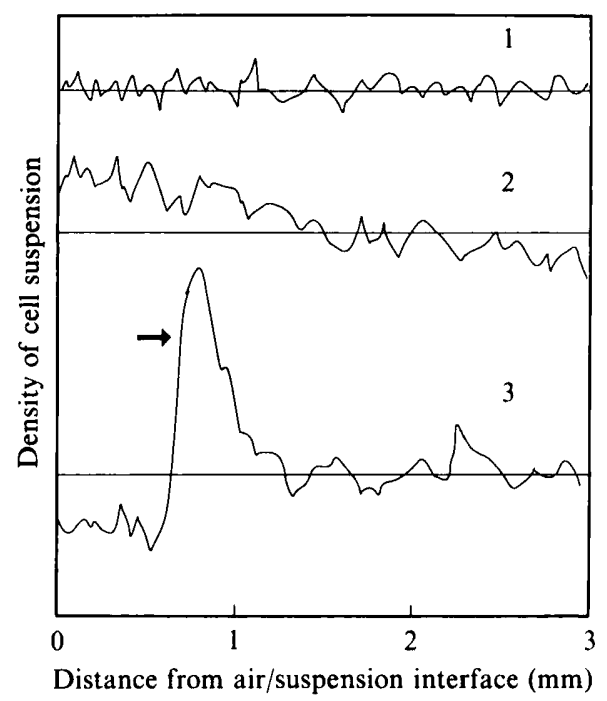

Fig. 2. Profiles of cell distribution in $A$. brasilense suspensions in the microchamber. (1) Cells with $20 \mathrm{mM}-\mathrm{KCN}$; oxygen gradient not preformed; $20 \mathrm{~min}$ incubation. (2) Cells with $20 \mathrm{mM}-\mathrm{KCN}$ in a pre-formed oxygen gradient; 20 min incubation. (3) Cells without $\mathrm{KCN}$; oxygen gradient not pre-formed; 2 min incubation. The arrow shows the peak corresponding to an aerotactic band. The ordinate is the density of a cell suspension measured with the microphotometer and is expressed in arbitrary units.

cell distribution in a pre-formed oxygen gradient was carried out after 20 min incubation with cyanide (Fig. 2). There was no attraction of the cells by anaerobic conditions: the cell density near the agarose block was less than in the middle of the suspension. Moreover, the bacteria showed a weak attraction to high oxygen concentration: the cell density near the air bubble was higher than in the middle of the suspension. The repulsion of the bacteria from the region of the agarose block should not have been caused by the action of glucose or gluconate (a product of glucose oxidation), as these have been reported to be a non-chemoeffector and an attractant, respectively, for $A$. brasilense (Reinhold et al., 1985; Zhulin et al., 1988).

These experimental data do not support the suggestion that a special receptor, separate from the redox chain, senses oxygen as a repellent, because there was no negative response to oxygen when the positive receptors (terminal oxidases of the redox chain) were inhibited by $\mathrm{KCN}$. The possible existence of such a receptor is not, however, excluded, because (i) cyanide might also inhibit this receptor and (ii) this receptor might detect toxic byproducts of oxygen reduction, rather than oxygen per se, as suggested by Shioi et al, (1987).

To avoid such byproducts a spatial gradient of an artificial electron acceptor was used in the experiments described below.

\section{Oxidized TMPD as an electron acceptor for the redox chain of $A$. brasilense}

Ferricyanide is an electron acceptor for the redox chain of Bacillus cereus and is also an attractant for this bacterium (Laszlo et al., 1984b). After addition of ferricyanide to a suspension of $A$. brasilense cells no changes in oxygen uptake were observed for a wide range of ferricyanide concentrations. This led us to speculate that the complex ferricyanide anion cannot permeate the outer membrane of $A$. brasilense, which is a Gramnegative bacterium in contrast to the Gram-positive $B$. cereus. This suggestion was supported by spectrophotometric measurements at $422 \mathrm{~nm}$ (the absorbance maximum for ferricyanide) of a dense bacterial suspension containing $0 \cdot 1 \mathrm{mM}$-ferricyanide against the same suspension without ferricyanide: no change in absorbance was observed. However, when $50 \mu \mathrm{M}$-TMPD was added to an $A$. brasilense cell suspension containing $1 \mathrm{~mm}$-ferricyanide, oxygen uptake by the cells stopped for a short period of time. In this case, TMPD seems to act as a carrier which transfers electrons from some components of the redox chain (most likely, those of the cytochrome $c$ group) to extracellular ferricyanide. Therefore, the possibility that cells would show taxis in a gradient of ferricyanide in the presence of TMPD was investigated.

\section{Behaviour of $A$. brasilense in a spatial gradient of ferricyanide in the presence of TMPD}

A spatial gradient of ferricyanide in isotropic TMPD was created in the microchamber, as described in Methods.

Formation of a distinct band (Fig. $3 b$ ), similar to an aerotactic band (Fig. $3 a$ ) was observed after 1-2 min incubation (Fig. 3). The distance between the band and the edge of an agarose block depended on the concentration of ferricyanide (Fig. 4). After 5-6 min (5 mMferricyanide in the gel) or 10-15 min (10 mm-ferricyanide in the gel) the tactic band widened and moved closer to the agarose block as a result of dispersion of the ferricyanide gradient and reduction of this compound by the cells. Cells in a control (without TMPD) were distributed uniformly in the suspension. All the above mentioned effects were identical in suspensions of cells from the mid-exponential $\left(\mathrm{OD}_{530}=0.6\right)$ and early exponential $\left(\mathrm{OD}_{530}=0.25\right)$ growth phases. This indicates that the described behaviour of the cells is typical for growth phases in which aerotactic behaviour also occurs.

The behaviour of $A$. brasilense cells in a gradient of ferricyanide in the presence of TMPD can be described as 'redox'-taxis, because the bacteria respond not to a concentration gradient, but to a 'redox' gradient of 

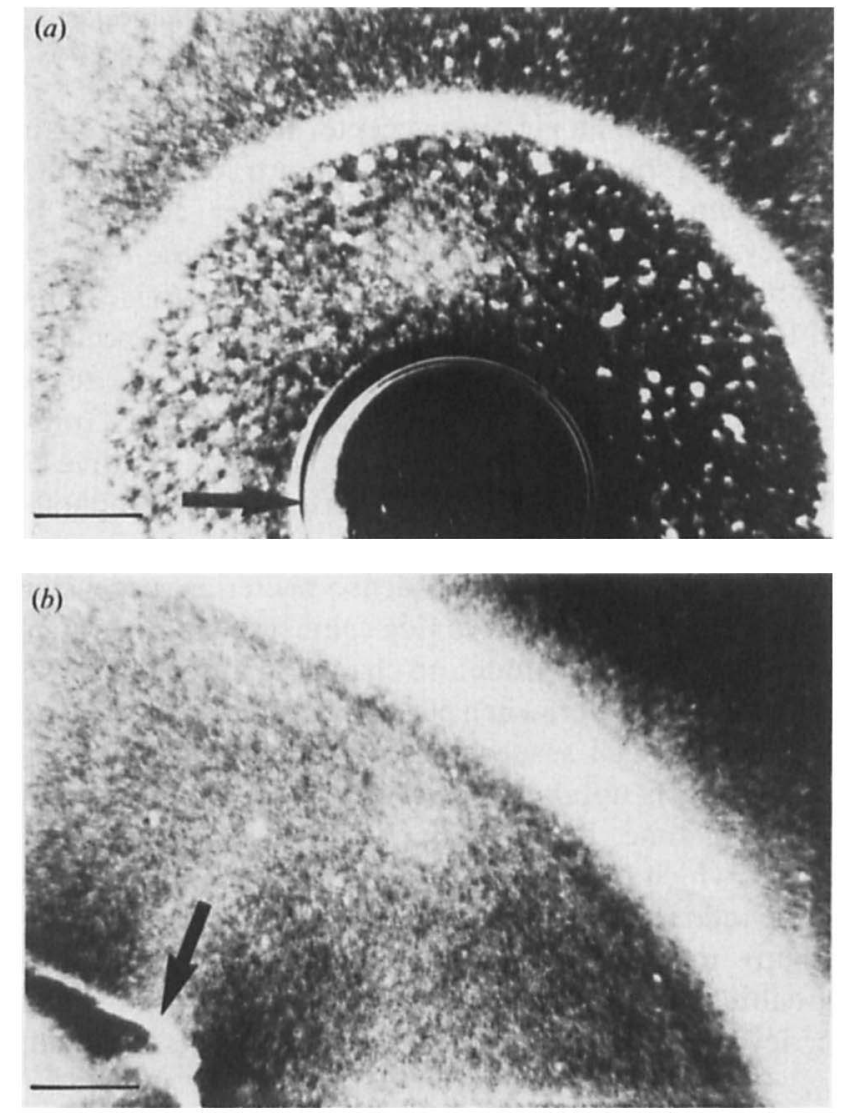

Fig. 3. Tactic bands in $A$, brasilense suspensions in the microchamber. (a) Aerotactic band formed in the suspension $\left(\mathrm{OD}_{530}=0.8\right)$ around an air bubble located in the microchamber; $2 \mathrm{~min}$ incubation. The arrow represents an air/suspension interface. (b) 'Redox'-tactic band formed in the suspension $\left(O D_{530}=1 \cdot 2\right)$ in response to a ferricyanide gradient in isotropic TMPD; concentration of ferricyanide in agarose, $10 \mathrm{mM}$; concentration of TMPD in agarose and in the suspension, $200 \mu \mathrm{M} ; 2$ min incubation. The arrow represents an agarose-block/suspension interface. Bars, $200 \mu \mathrm{m}$.

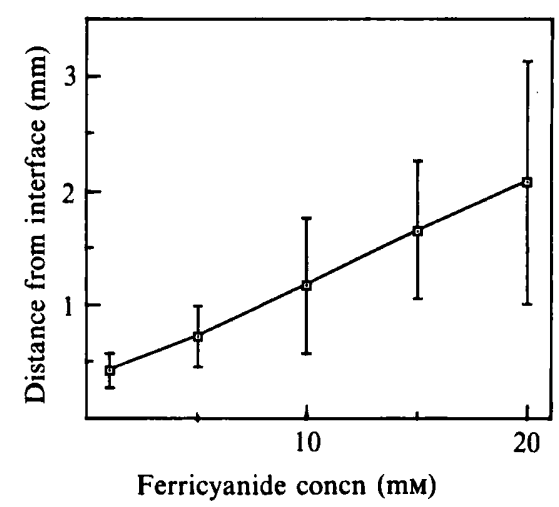

Fig. 4. Formation of a 'redox'-tactic band in a suspension of $A$. brasilense cells depending upon the concentration of ferricyanide in an agarose block in the microchamber. Concentration of TMPD in agarose and in the suspension, $200 \mu \mathrm{M}$. Each point represents the mean of six replicates. Bars represent standard errors.
TMPD. This behaviour showed all the features of aerotaxis. In a 'redox' gradient of TMPD, as in a spatial gradient of oxygen, bacteria collected in a very narrow region of optimal redox potential. Migration of the tactic band of $A$. brasilense in the 'redox' gradient depended on the oxidative ratio (concentration of ferricyanide) in the same manner as the migration of an aerotactic band of $S$. typhimurium depends on oxygen concentration in a spatial gradient (Shioi et al., 1987).

\section{Effects of inhibitors of ubiquinol : cytochrome $c$ oxidoreductase on oxygen taxis in a spatial gradient}

Ubiquinol:cytochrome $c$ oxidoreductase ( $b c_{1}$-complex) in $A$. brasilense has been identified as a specific point of the redox chain which donates electrons to cytochrome $o$. Inhibitors of the $b c_{1}$-complex also inhibit aerotaxis in $A$. brasilense in a temporal assay, identifying cytochrome $o$ as a chemoreceptor for oxygen (Reiner \& Okon, 1986). This is in contrast with results obtained with other bacteria. It has been suggested that a chemoreceptor for oxygen might measure electron flow or protonmotive force rather than binding of oxygen to a specific terminal oxidase (Taylor, 1983; Laszlo et al., 1984b; Armitage et al., 1985; Shioi et al., 1988).

We studied the influence of antimycin A and 2-heptyl4-hydroxyquinoline $N$-oxide (HQNO) on aerotaxis of $A$. brasilense in a spatial oxygen gradient. These two inhibitors were used in a temporal assay in the work of Reiner \& Okon (1986). Both antimycin A and HQNO inhibited respiration in $A$. brasilense by no more than $50 \%$ of the initial level of endogenous respiration, even when used in very high concentrations ( $20 \mu \mathrm{M}$ and more) and neither compound inhibited aerotactic band formation. An aerotactic band was formed further away from an air bubble and the time required for its formation was greater than in a control suspension without inhibitors. Activation of cell respiration by $10 \mathrm{~mm}$-ascorbate with TMPD $(50 \mu \mathrm{M})$ or by $5 \mathrm{mM}$-malate caused the formation of an aerotactic band at the same distance from an air/suspension interface as in a control (cells in buffer without substrates and inhibitors).

Additional examination of the role of the $b c_{1}$-complex in aerotactic behaviour of $A$. brasilense was carried out using myxothiazol. The $b c_{1}$-complex is a highly conserved region of redox chains: its structure and function are very similar in different bacteria and in mitochondria. The action of myxothiazol on $A$. brasilense would be expected to be on the $b c_{1}$-complex as in other bacteria (Trumpower, 1990). Myxothiazol inhibits ubiquinol oxidation by the iron-sulphur protein, whereas antimycin $A$ and $H Q N O$ inhibit ubiquinone reduction by cytochrome $b$. Therefore, the combined action of these 
inhibitors should completely block electron flow through this branch of the redox chain. In our experiments myxothiazol $(20 \mu \mathrm{M})$ inhibited oxygen uptake by the cells to the same extent as antimycin A and HQNO (about $50 \%$ of initial endogenous respiration) and did not inhibit aerotactic band formation. Simultaneous addition of $20 \mu \mathrm{M}-\mathrm{HQNO}$ and $20 \mu \mathrm{M}-\mathrm{myx}$ othiazol had the same effect. These results show that under conditions where the $b c_{1}$-complex is completely inhibited, other functioning branches of the electron transport chain (about $50 \%$ of initial respiratory level) maintain aerotaxis in A. brasilense.

Addition of antimicin A $(20 \mu \mathrm{M})$ to a cell suspension in a 'redox' gradient of ferricyanide in TMPD prevented formation of an aerotactic band. This indicates that the $b c_{1}$-complex is responsible for electron flow towards this artificial electron acceptor.

The results obtained during this study show that in $A$. brasilense as in other bacteria, sensing of oxygen and other electron acceptors is dependent on electron flow through the redox chain (and/or consequent changes in protonmotive force) rather than on changes in the reduction state of a specific terminal oxidase (Taylor, 1983; Armitage et al., 1985; Shioi et al., 1988). We also suggest that not only the positive aerotactic response, but also the negative aerotactic response is based on the functioning of the redox chain and that a protonmotive force sensor, or protometer (Glagolev, 1980), might be involved in sensing oxygen as an attractant and as a repellent.

We are grateful to Drs Boris Schwarzburd (our institute) and Sergei Bibikov (Moscow State University) for their help during the work and useful comments and to Professor Vladimir Ignatov (our institute) for general support of this work. We wish to thank Dr Jocelyn Foster (University of Oxford) for her help during the preparation of the manuscript.

We give special thanks to Dr Judith Armitage (University of Oxford) and Professor Barry Taylor (University of Loma Linda, California) for stimulating discussions and critical reading of the manuscript.

This work was supported by a grant from the Presidium of the USSR Academy of Sciences and in part by a grant from All-Union Research Institute for Agricultural Microbiology (Leningrad).

\section{References}

ADLER, J. (1973). A method for measuring chemotaxis and use of the method to determine optimum conditions for chemotaxis by Escherichia coli. Journal of General Microbiology 74, 77-91.
Armitage, J. P., Ingham, C. \& Evans, M. C. W. (1985). Role of proton motive force in phototactic and aerotactic responses of Rhodopseudomonas sphaeroides. Journal of Bacteriology 161, 967-972.

Barak, R., NUR, I., OKon, Y. \& HENIS, Y. (1982). Aerotactic response of Azospirillum brasilense. Journal of Bacteriology 152, 643-649.

GlaGolev, A. N. (1980). Reception of the energy level in bacterial taxis. Journal of Theoretical Biology 82, 171-185.

LASZlo, D. J. \& TAYLOR, B. L. (1981). Aerotaxis in Salmonella typhimurium: role of electron transport. Journal of Bacteriology 145, 990-1001.

laszlo, D. J., Fandrich, B. L., Sivaram, A., Chance, B. \& Taylor, B. L. $(1984 a)$. Cytochrome $o$ as a terminal oxidase and receptor for aerotaxis in Salmonella typhimurium. Journal of Bacteriology 159, 663-667.

Laszlo, D. J., Niwano, M., Goral, W. W. \& Taylor, B. L. (1984b). Bacillus cereus electron transport and proton motive force during aerotaxis. Journal of Bacteriology 159, 820-824.

Martinez-Drets, G., Del Gallo, M., Burpee, C. \& Burris, R. H. (1984). Catabolism of carbohydrates and organic acids and expression of nitrogenase by azospirilla. Journal of Bacteriology 159, 80-85.

NELSON, L. M. \& KNOWLES, R. (1978). Effect of oxygen and nitrate on nitrogen fixation and denitrification by $A$ zospirillum brasilense grown in continuous culture. Canadian Journal of Microbiology 24, 13951403.

OKON, Y. \& KAPULNIK, Y. (1986). Development and function of Azospirillum-inoculated roots. Plant and Soil 90, 3-16.

Okon, Y., CakmakCI, L., Nur, I. \& Chet, I. (1980). Aerotaxis and chemotaxis of Azospirillum brasilense: a note. Microbial Ecology 6, $277-280$

REINER, O. \& OKON, Y. (1986). Oxygen recognition in aerotactic behaviour of Azospirillum brasilense Cd. Canadian Journal of Microbiology 32, 829-834.

REINHOLd, B., HUREK, T. \& FENDRIK, I. (1985). Strain-specific chemotaxis of Azospirillum spp. Journal of Bacteriology 162, 190-195.

Rowsell, E. H., Smith, J. M., Wolfe, A., Conley, M. P., Taylor, B. L. \& BERG, H. C. (1988). Convergence of the methylationdependent and methylation-independent pathways for bacterial chemotax is. Federation of American Societies for Experimental Biology Journal 2, A574.

SHIOI, J. \& TAYLOR, B. L. (1984). Oxygen taxis and proton motive force in Salmonella typhimurium. Journal of Biological Chemistry 259, 10983-10988.

ShIOI, J., DANG, V. \& TAYLOR, B. L. (1987). Oxygen as attractant and repellent in bacterial chemotaxis. Journal of Bacteriology 169, 31183123.

Shiol, J., Tribhuwan, R. C., Berg, S. T. \& Taylor, B. L. (1988). Signal transduction in chemotaxis to oxygen in Escherichia coli and Salmonella typhimurium. Journal of Bacteriology 170, 5507-5511.

TAYLOR, B. L. (1983a). Role of proton motive force in sensory transduction in bacteria. Annual Review of Microbiology 37, 551-573.

TAYLOR, B. L. (1983b). How do bacteria find the optimal concentration of oxygen? Trends in Biochemical Sciences 8, 438-441.

TRUMPOWER, B. L. (1990). Cytochrome $b c_{1}$ complexes of microorganisms. Microbiological Reviews 54, 101-129.

Zhulin, I. B., Tretyakova, S. E. \& Ignatov, V. V. (1988). Chemotaxis of Azospirillum brasilense towards compounds typical of plant root exudates. Folia Microbiologica 33, 277-280.

Zhulin, I. B., Gibel, I. B. \& Ignatov, V. V. (1991). A rapid method for the measurement of bacterial chemotaxis. Current Microbiology 22, 307-310. 